\title{
Glucosamine promotes chondrocyte proliferation via the Wnt/B-catenin signaling pathway
}

\author{
YUHUAN MA ${ }^{1}$, WENWEI ZHENG ${ }^{1}$, HOUHUANG CHEN $^{2}$, XIANG SHAO $^{2}$, PINGDONG LIN $^{1}$, \\ XIANXIANG LIU ${ }^{2}$, XIHAI LI ${ }^{2,3}$ and HONGZHI YE ${ }^{2,3}$ \\ ${ }^{1}$ College of Pharmacy; ${ }^{2}$ Academy of Integrative Medicine; ${ }^{3}$ Fujian Key Laboratory of Integrative Medicine on Geriatrics, \\ Fujian University of Traditional Chinese Medicine, Fuzhou, Fujian 350122, P.R. China
}

Received July 19, 2016; Accepted January 22, 2018

DOI: $10.3892 /$ ijmm.2018.3587

\begin{abstract}
The present study investigated the mechanism underlying the effects of glucosamine $(\mathrm{GlcN})$ on the proliferation of chondrocytes isolated from the knee cartilage of Sprague-Dawley rats. Chondrocytes were treated with various concentrations of GlcN or without GlcN. The effects of GlcN on chondrocyte proliferation were determined using reverse transcription-polymerase chain reaction, western blot analysis and immunohistochemistry. The results indicated that GlcN significantly improved chondrocyte viability, accelerated $\mathrm{G}_{1} / \mathrm{S}$ transition during progression of the cell cycle and promoted the expression of cell cycle regulatory proteins, including cyclin D1, cyclin-dependent kinase (CDK)4 and CDK6, thus indicating that GlcN may promote chondrocyte proliferation. Furthermore, GlcN upregulated the expression levels of Wnt-4, Frizzled-2 and $\beta$-catenin, and downregulated the expression of glycogen synthase kinase-3. GlcN also promoted $\beta$-catenin translocation; $\beta$-catenin is able to activate numerous downstream target genes, including cyclin D1. To determine the role of the $\mathrm{Wnt} / \beta$-catenin signaling pathway in chondrocyte proliferation, the Wnt $/ \beta$-catenin signaling pathway was inhibited using Dickkopf-1 (DKK-1), after which chondrocytes were treated with GlcN. The results demonstrated that the expression levels of $\beta$-catenin and cyclin D1 were decreased in chondrocytes treated with DKK-1 and GlcN. These results suggested that GlcN may promote chondrocyte proliferation via the $\mathrm{Wnt} / \beta$-catenin signaling pathway.
\end{abstract}

\section{Introduction}

Osteoarthritis (OA) is a chronic disease that affects the joint cartilage of middle-aged and elderly individuals, which is

Correspondence to: Professor Xihai Li or Professor Hongzhi Ye, Academy of Integrative Medicine, Fujian University of Traditional Chinese Medicine, 1 Qiuyang Road, Minhou Shangjie, Fuzhou, Fujian 350122, P.R. China

E-mail: lixihai79dahai@163.com

E-mail: yelin0930@163.com

Key words: chondrocyte, cell cycle, proliferation, signaling pathway, osteoarthritis associated with degradation of articular cartilage (1). Articular cartilage is an avascular tissue with limited regenerative ability, which is composed of chondrocytes and extracellular matrix (ECM) components. As the only cell type in articular cartilage, chondrocytes control the balance between catabolism and anabolism, in order to maintain appropriate functioning of the ECM $(2,3)$. During the process of OA, chondrocyte death is associated with degradation of the ECM and calcification, thus suggesting a role for cell death in the pathogenesis of OA. Therefore, enhancing chondrocyte proliferation may be a potential method to inhibit the development and progression of OA.

As a vital process for cell proliferation, the cell cycle is composed of four key phases: $G_{1}, S$ (DNA replication), $G_{2}$ and $\mathrm{M}$ (mitosis). Between the $\mathrm{S}$ and $\mathrm{M}$ phases, there are two gaps, $G_{1}$ prior to the $S$ phase and $G_{2}$ prior to the $M$ phase (4). The activity of cyclin D1, and its binding partners cyclin-dependent kinase (CDK)4/6, controls the progression through every phase of the cell cycle and is implicated in chondrocyte proliferation $(5,6)$. The normal function of cartilage is affected by numerous signaling pathways, including the Wnt/ $\beta$-catenin signaling pathway (7-9). The Wnt/ $\beta$-catenin signaling pathway serves an important role in the regulation and control of cell proliferation and maintenance of phenotypic characteristics, and is important for the regulation of cartilage function (10). Binding of Wnt proteins to cell surface receptor complexes, which are composed of Frizzled proteins and low-density lipoprotein receptor-related proteins (LRP) $5 / 6$, results in the activation of dishevelled, after which glycogen synthase kinase-3 $\beta$ (GSK-3 $\beta$ ) activity and $\beta$-catenin phosphorylation are inhibited. Non-phosphorylated $\beta$-catenin accumulates in the cytoplasm and translocates to the nucleus, where it binds to the transcription factors T-cell factor (TCF) and lymphoid enhancer factor (LEF), in order to regulate target gene expression $(11,12)$. These factors accelerate cell cycle progression by accommodating the expression of cyclin D1 (13). It has previously been reported that the $\mathrm{Wnt} / \beta$-catenin signaling pathway acts upstream of cyclin D1 (14). Therefore, the Wnt/ $\beta$-catenin pathway may have an important role in cell proliferation via the regulation of cyclin D1.

Glucosamine $(\mathrm{GlcN})$ is an amino-monosaccharide synthesized from glucose, which is used for the biosynthesis of glycoproteins and glycosaminoglycans (15). GlcN is a natural 
compound present in the majority of human tissues, with the highest concentrations detected in cartilage (16). GlcN is widely used in the clinical treatment of OA, due to its fundamental role in stimulating the metabolism of chondrocytes $(17,18)$. However, the molecular mechanisms underlying the effects of GlcN on chondrocytes remain unclear. Therefore, the present study aimed to clarify the mechanisms underlying the effects of GlcN on chondrocytes.

\section{Materials and methods}

Preparation of GlcN. GlcN was obtained from Shanghai Aladdin Biochemical Technology Co., Ltd. (Shanghai, China) and was dissolved in Dulbecco's modified Eagle's medium (DMEM) supplemented with $10 \%$ fetal bovine serum (FBS) (both from HyClone; GE Healthcare Life Sciences, Logan, UT, USA). Subsequently, GlcN was filtered through a $0.22-\mu \mathrm{m}$ filter.

Isolation, culture and identification of chondrocytes. Male, 4-week-old, Sprague-Dawley specific pathogen-free rats (weight, 200-300 g) were purchased from Shanghai SLAC Laboratory Animal Co., Ltd. (Shanghai, China). The care and use of animals in the present study were conducted in strict accordance with the Guide for the Care and Use of Laboratory Animals of Fujian University of Traditional Chinese Medicine (Fuzhou, China). The present study was approved by the Ethics Committee of Fujian University of Traditional Chinese Medicine. Sprague-Dawley rats were sacrificed using carbon dioxide (cage size, $7 \times 11 \times 5$ inches; flow rate, $1.3 \mathrm{l} / \mathrm{min}$ ), according to the Guide for the Care and Use of Laboratory Animals.

Chondrocytes were isolated from the knee cartilage of Sprague-Dawley rats and were cultured as previously described (19). Briefly, four Sprague-Dawley rats were sacrificed, and their knees were stripped and soaked in $75 \%$ ethanol for $15 \mathrm{~min}$. The articular cartilage was cut open in the bilateral knee joints, collected with a blade and washed with PBS (HyClone; GE Healthcare Life Sciences) three times under sterile conditions. The cartilage samples were cut into $1-\mathrm{mm}^{3}$ sections and digested with $0.2 \%$ collagenase II (Sigma-Aldrich; Merck KGaA, Darmstadt, Germany) at $37^{\circ} \mathrm{C}$ in an incubator containing $5 \% \mathrm{CO}_{2}$. The supernatant fluid was collected every $2 \mathrm{~h}$, and was centrifuged at $110 \mathrm{x} \mathrm{g}$ for $5 \mathrm{~min}$. The isolated cells were resuspended in DMEM containing 10\% FBS, and were cultured in $50 \mathrm{ml}$ culture flasks containing $4 \mathrm{ml}$ DMEM supplemented with $10 \% \mathrm{FBS}$ at $37^{\circ} \mathrm{C}$ in a $5 \% \mathrm{CO}_{2}$ incubator. Primary chondrocytes were termed passage 0 (P0), and $\mathrm{P} 2$ chondrocytes at $\sim 80 \%$ confluence were used in subsequent experiments. P2 chondrocytes were identified by collagen II immunohistochemistry (20). Briefly, the cells were seeded onto a sterilized round coverslip and placed in a 6 -well plate $\left(2 \times 10^{4}\right.$ cells/well); the cells were cultured at $37^{\circ} \mathrm{C}$ in a $5 \% \mathrm{CO}_{2}$ incubator for $48 \mathrm{~h}$. Subsequently, the cells were fixed with $4 \%$ paraformaldehyde (Sigma-Aldrich; Merck KGaA) for $30 \mathrm{~min}$ at $4^{\circ} \mathrm{C}$ and blocked with $10 \%$ bovine serum albumin (BSA) (Sigma-Aldrich; Merck $\mathrm{KGaA}$ ) for $1 \mathrm{~h}$. The round coverslip was then incubated with a type II collagen rabbit polyclonal antibody (dilution 1:500; BS1071; Bioworld Technology, Inc., St. Louis Park, MN, USA) overnight at $4^{\circ} \mathrm{C}$. The round coverslip was then incubated with horseradish peroxidase (HRP)-conjugated affinipure goat anti-rabbit immunoglobulin (Ig)G (dilution: 1:200; ZB-2301) for $30 \mathrm{~min}$, followed by incubation with diaminobenzidine (ZLI-9018) (both from OriGene Technologies, Inc., Beijing, China) for $5 \mathrm{~min}$ at room temperature. The slides were finally counterstained with hematoxylin (Sigma-Aldrich; Merck $\mathrm{KGaA}$ ) and were dehydrated. Images were captured under a light microscope (BH2; Olympus Corporation, Tokyo, Japan). According to the MTT assay, chondrocytes were treated with 0, 100, 200 and $300 \mu \mathrm{g} / \mathrm{ml} \mathrm{GlcN}$ for $72 \mathrm{~h}$. In order to further verify the mechanisms involved, chondrocytes were treated with $0.2 \mu \mathrm{g} / \mathrm{ml}$ Dickkopf-1 (DKK-1; R\&D Systems, Inc., Minneapolis, MN, USA) and were treated with GlcN (200 $\mu \mathrm{g} /$ $\mathrm{ml}$ ) in the presence or absence of DKK-1 for $72 \mathrm{~h}$ at $37^{\circ} \mathrm{C}$.

Evaluation of cell viability by MTT assay. The P2 chondrocytes were plated onto a 96-well plate at a density of $1.0 \times 10^{4} / \mathrm{ml}$ and were cultured for $24 \mathrm{~h}$. The cells were then treated with various concentrations of GlcN $(50,100,200$, 300 and $600 \mu \mathrm{g} / \mathrm{ml}$ ) for 24 or $72 \mathrm{~h}$. Subsequently, $100 \mu \mathrm{l} \mathrm{MTT}$ ( $1 \mathrm{mg} / \mathrm{ml}$ in PBS) was added to each well and was incubated at $37^{\circ} \mathrm{C}$ for $4 \mathrm{~h}$. The supernatant was then removed and $150 \mu \mathrm{l}$ dimethyl sulfoxide was added to dissolve the formazan. The solution was agitated for $10 \mathrm{~min}$ and the optical density was measured at $490 \mathrm{~nm}$ using an ELISA reader (model ELx800; BioTek Instruments, Inc., Winooski, VT, USA).

Cell cycle analysis. Following treatment with GlcN, chondrocytes were collected and chondrocyte density was adjusted to $1 \times 10^{6} / \mathrm{ml}$. The process of staining was performed using a cell cycle assay kit (BD Cycletest ${ }^{\mathrm{TM}}$ Plus DNA reagent kit; BD Biosciences, Franklin Lakes, NJ, USA) according to the manufacturer's protocol. Subsequently, the cells were analyzed using fluorescence-activated cell sorting (FACSCalibur ${ }^{\mathrm{TM}}$; BD Biosciences, San Diego, CA, USA). The percentage of cells in the different phases of the cell cycle, including $G_{0} / G_{1}, S$, $\mathrm{G}_{2}$ and $\mathrm{M}$ phases, was calculated using ModFit software 4.0 (Verity Software House, Topsham, ME, USA) .

RNA extraction and reverse transcription-polymerase chain reaction $(R T-P C R)$ analysis. Following treatment with GlcN, total RNA was extracted using TRIzol ${ }^{\circledR}$ reagent (Invitrogen; Thermo Fisher Scientific, Inc., Waltham, MA, USA) according to the manufacturer's protocol. Total RNA $(1 \mu \mathrm{g})$ was reverse transcribed into cDNA using a RevertAid First Strand cDNA Synthesis kit (Thermo Fisher Scientific, Inc.) according to the manufacturer's protocol. The following primers were used for PCR to determine the mRNA expression levels of CDK4, CDK6, cyclin D1, Wnt-4, $\beta$-catenin, Frizzled-2 and GSK-3 $\beta$ : CDK4, forward 5'-GAA GAC GAC TGG CCT CGA GA-3', reverse, 5'-ACT GCG CTC CAG ATT CCT CC-3'; CDK6, forward 5'-TTG TGA CAG ACA TCG ACG AG-3', reverse 5'-GAC AGG TGA GAA TGC AGG TT-3'; cyclin D1, forward 5'-AAT GCC AGA GGC GGA TGA GA-3', reverse 5'-GCT TGT GCG GTA GCA GGA GA-3'; Wnt-4, forward 5'-TCA GCC CAC AGG GTT TCC A-3', reverse 5'-CGC TCG CCA GCA TGT CTT T-3'; $\beta$-catenin, forward 5'-AAG GAA GCT TCC AGA CAT GC-3', reverse 5'-AGC TTG CTC TCT TGA TTG CC-3'; Frizzled-2, forward 5'-TCG AGG CCA ATT CGC AGT A-3', reverse 5'-CAG GAA GGA TGT GCC GAT G-3'; 


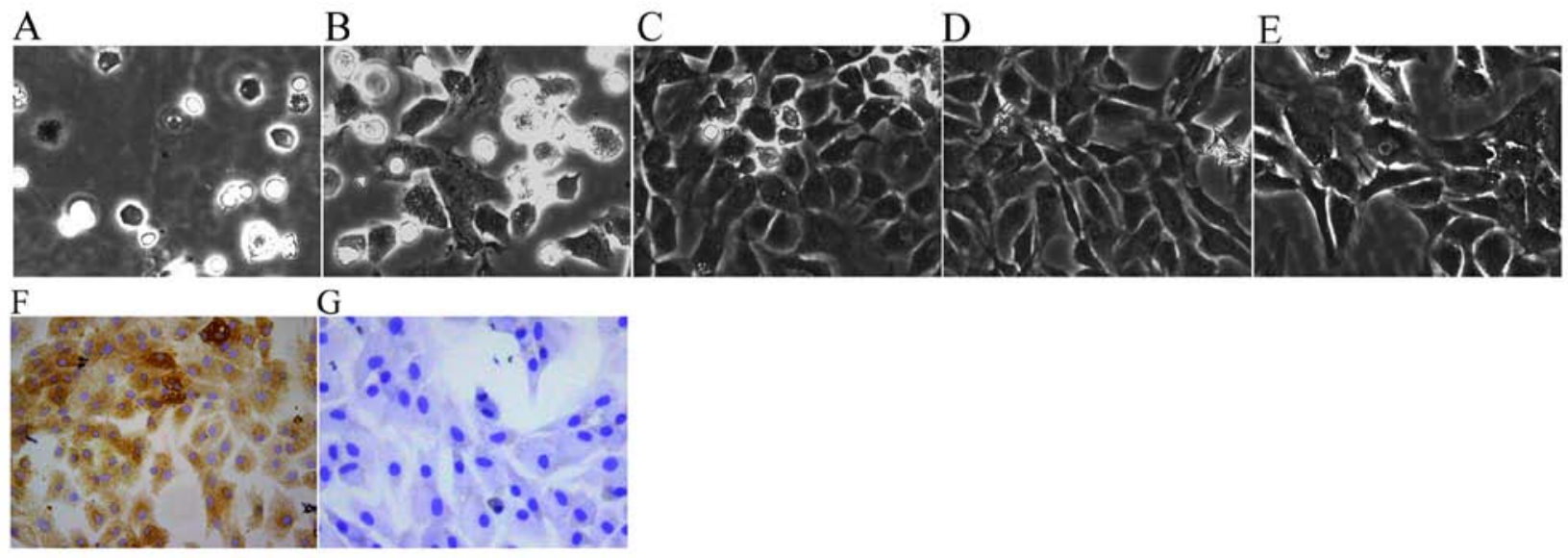

Figure 1. Morphology and identification of chondrocytes (original magnification, x200). Primary chondrocytes cultured for (A) 24 h, and (B) 3 and (C) 6 days . (D) First passage chondrocytes cultured for 3 days. (E) Second passage chondrocytes cultured for 3 days. (F) Second passage chondrocytes cultured for 4 days were identified by collagen II immunohistochemistry. (G) Negative control cells also underwent collagen II immunohistochemistry.

GSK-3 $\beta$, forward 5'-AAA GTG CAT CGC TGG CTT A-3', reverse 5'-GTC GAC GGT TTG TTT CCA AT-3'; and $\beta$-actin, forward 5'-CAC CCG CGA GTA CAA CCT TC-3' and reverse 5'-CCC ATA CCC ACC ATC ACA CC-3'. The thermocycling conditions (annealing temperature, annealing time and number of cycles) were as follows: Wnt $-4: 57^{\circ} \mathrm{C}, 45 \mathrm{sec}, 35$ cycles; Frizzeld-2: $58^{\circ} \mathrm{C}, 45 \mathrm{sec}, 35$ cycles; Gsk-3 $\beta$ : $60^{\circ} \mathrm{C}, 30 \mathrm{sec}$, 28 cycles; $\beta$-catenin: $60^{\circ} \mathrm{C}, 45 \mathrm{sec}, 35$ cycles; Cyclin D1: $55^{\circ} \mathrm{C}$, $30 \mathrm{sec}, 35$ cycles; $\mathrm{CDK} 4: 60^{\circ} \mathrm{C}, 40 \mathrm{sec}, 32$ cycles; CDK6: $60^{\circ} \mathrm{C}$, $30 \mathrm{sec}, 30$ cycles. The DNA bands were examined via gel electrophoresis (1.5\% agarose) using a gel documentation system (Model Gel Doc 2000; Bio-Rad Laboratories, Inc., Hercules, CA, USA). $\beta$-actin was used as an internal control.

Western blot analysis. Following treatment with $\mathrm{GlcN}$, proteins were collected from the cells using radioimmunoprecipitation assay lysis buffer supplemented with $1 \mathrm{mM}$ phenylmethanesulfonyl fluoride (both from Beyotime Institute of Biotechnology, Shanghai, China). Protein concentration was quantified using the bicinchoninic acid assay method. Proteins $(20 \mu \mathrm{g})$ were separated by $12 \%$ SDS-PAGE and were transferred onto polyvinylidene fluoride membranes (Thermo Fisher Scientific, Inc.). After transfer, the membranes were blocked in 5\% skimmed milk for $1 \mathrm{~h}$ at room temperature and were incubated overnight at $4^{\circ} \mathrm{C}$ with the following primary antibodies (1:1,000): CDK4 (sc-260), CDK6 (sc-177), Wnt-4 (sc-5214), Frizzled-2 (sc-68327), cyclin D1 (sc-718), $\beta$-actin (sc-47778) (Santa Cruz Biotechnology, Inc., Dallas, TX, USA), GSK-3 $\beta$ (9315) and $\beta$-catenin (9582) (Cell Signaling Technology, Inc., Beverly, MA, USA). Membranes were then incubated with HRP-conjugated secondary antibodies [anti-goat (dilution 1:500; ZDR-5105); anti-rabbit (dilution 1:500; ZDR-5306); anti-mouse (dilution 1:1,000; ZDR-5109), Beijing Zhongshan Golden Bridge Biotechnology Co., Ltd., Beijing, China] at room temperature for $1 \mathrm{~h}$. The immunocomplexes were detected using a Bio-Rad ChemiDoc $\mathrm{XRS}^{+}$ imaging system (Image Lab 3.0; Bio-Rad Laboratories, Inc.). $\beta$-actin was used as an internal control.

Immunohistochemistry. Following treatment with GlcN, chondrocytes were fixed with $4 \%$ paraformaldehyde for
$15 \mathrm{~min}$ at room temperature and were permeabilized with $1 \%$ Triton X-100 in PBS for $10 \mathrm{~min}$ at room temperature. Subsequently, the chondrocytes, fixed with paraformaldehyde and permeabilized with $1 \%$ Triton X-100 in PBS, were washed three times and were blocked with 5\% BSA in PBS for $1 \mathrm{~h}$ at room temperature. After blocking, the chondrocytes were incubated with rabbit anti- $\beta$-catenin antibody (dilution 1:200; sc-7199; Santa Cruz Biotechnology, Inc.) overnight at $4^{\circ} \mathrm{C}$. After exposure to the primary antibody, the chondrocytes were washed and incubated with the corresponding secondary antibody (DyLight 488 AffiniPure Goat Anti-Rabbit IgG) for $1 \mathrm{~h}$ at room temperature. Finally, DAPI was used to stain cell nuclei at room temperature for $5 \mathrm{~min}$. The signal was visualized and images were acquired using a fluorescence microscope (LSM710; Carl Zeiss AG, Oberkochen, Germany).

Statistical analysis. Data are presented as the means \pm standard deviation. The experiments were repeated 3 times. Data were processed using SPSS software version 18.0 (SPSS, Inc., Chicago, IL, USA) and were analyzed with Student's t-test or analysis of variance. The multiple comparisons tests used were least significant difference (LSD) and Dunnett tests. $\mathrm{P}<0.05$ was considered to indicate a statistically significant difference.

\section{Results}

Morphology and characteristics of chondrocytes. Chondrocyte morphology has been described in previous studies $(21,22)$; the chondrocytes in the present study exhibited a spherical, fusiform and slabstone shape, which is typical of chondrocytes (Fig. 1). The newly isolated chondrocytes were small and round when first suspended in DMEM. After being cultured for $2 \mathrm{~h}$, the chondrocytes gradually attached themselves to the culture flask (Fig. 1A). After being cultured for 3 days, the volumes of adherent cells became larger and some cells began to elongate and form a fusiform shape (Fig. 1B). After 6 days of proliferation, the cells coated the whole bottom of the culture flask (Fig. 1C). P1 and P2 chondrocytes spread across the flask more rapidly and usually reached $80-90 \%$ density within $\sim 5$ days (Fig. 1D and E). The cytoplasm of P2 chondrocytes was stained brown, which indicated that the P2 chondrocytes exhibited a more typical chondrocyte 

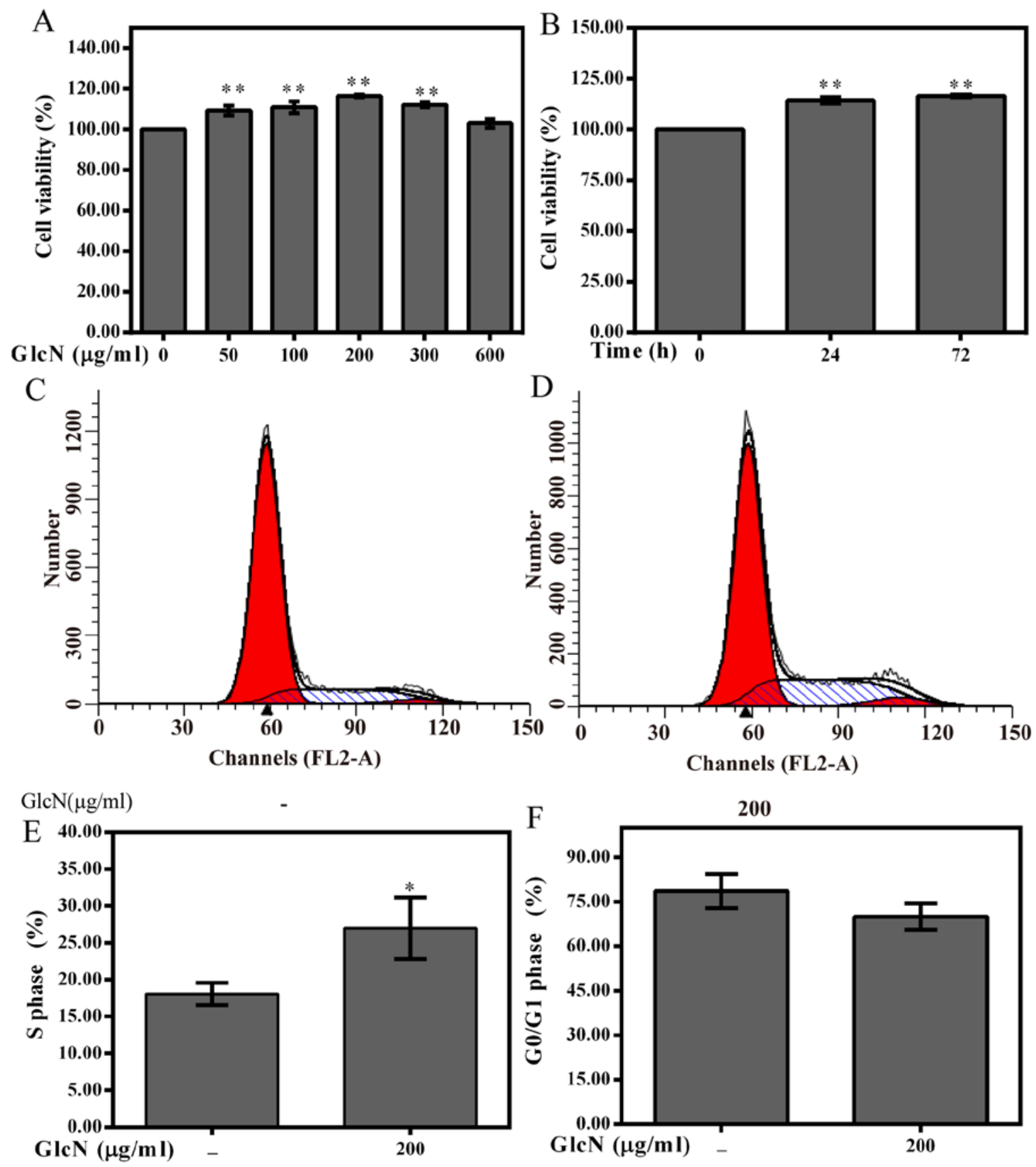

Figure 2. GlcN promotes chondrocyte proliferation. (A) Chondrocytes were treated with various concentrations of GlcN for $72 \mathrm{~h}$. (B) Chondrocytes were treated with $100 \mu \mathrm{g} / \mathrm{ml} \mathrm{GlcN}$ for 24 and $72 \mathrm{~h}$. (C and D) Chondrocytes were treated with or without GlcN and were stained with propidium iodide followed by fluorescence-activated cell sorting analysis. Percentage of chondrocytes in (E) S phase and $(F) G_{0} / G_{1}$ phase following treatment with or without GlcN. Data are presented as the means \pm standard deviation. ${ }^{*} \mathrm{P}<0.05,{ }^{* * *} \mathrm{P}<0.01$ compared with the untreated cells. GlcN, glucosamine.

morphology and contained large levels of collagen II (Fig. 1F) compared with in the negative control cells (Fig. 1G). Therefore, in view of the typical characteristics of $\mathrm{P} 2$ cells, $\mathrm{P} 2$ chondrocytes were used in subsequent experiments.

GlcN enhances chondrocyte viability and promotes cell cycle progression. To investigate whether GlcN exerts effects on chondrocyte viability, chondrocytes were treated with various concentrations of $\mathrm{GlcN}(50,100,200,300$ and $600 \mu \mathrm{g} / \mathrm{ml}$ ) for $72 \mathrm{~h}$ or with $100 \mu \mathrm{g} / \mathrm{ml} \mathrm{GlcN}$ for the indicated time periods (Fig. 2). GlcN treatment promoted the viability of cells in a dose- and time-dependent manner (Fig. 2A and B). According to the MTT assay results, cell viability was mark- edly enhanced following treatment with $200 \mu \mathrm{g} / \mathrm{ml} \mathrm{GlcN}$ for $72 \mathrm{~h}$; therefore, $0,100,200$ and $300 \mu \mathrm{g} / \mathrm{ml} \mathrm{GlcN}$ and $72 \mathrm{~h}$ were set as variables for further experimentation.

As shown in Fig. 2C-F, the percentage of GlcN-treated chondrocytes in the $G_{0} / G_{1}$ phase was reduced, whereas the percentage of cells in S phase was increased compared with in the untreated chondrocytes. Furthermore, the present study investigated whether cell cycle progression was associated with an increase in the protein expression levels of cyclins and CDKs. The results indicated that GlcN upregulated the mRNA and protein expression levels of cyclin D1, CDK4 and CDK6 (Fig. 3). These results indicated that GlcN caused an increase of cell proliferation. 
A

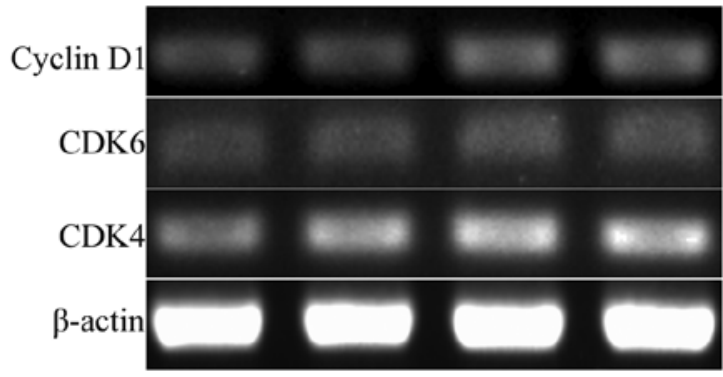

$\mathrm{C}$

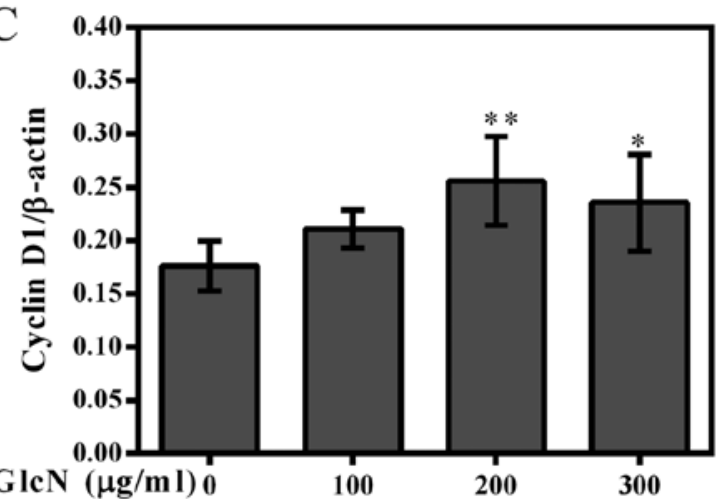

E

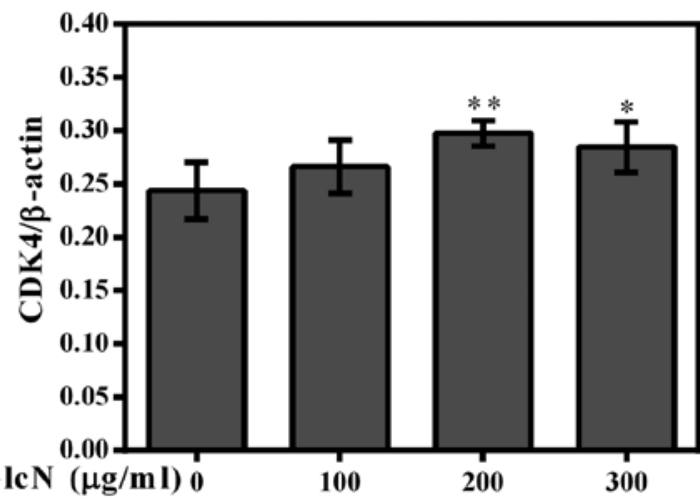

G

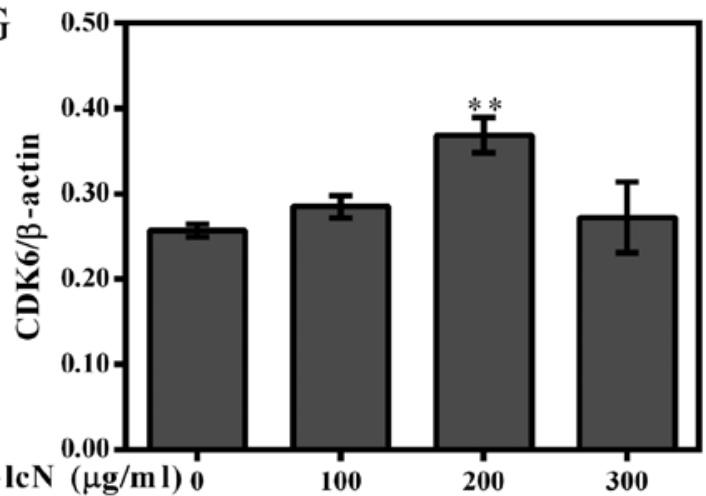

B

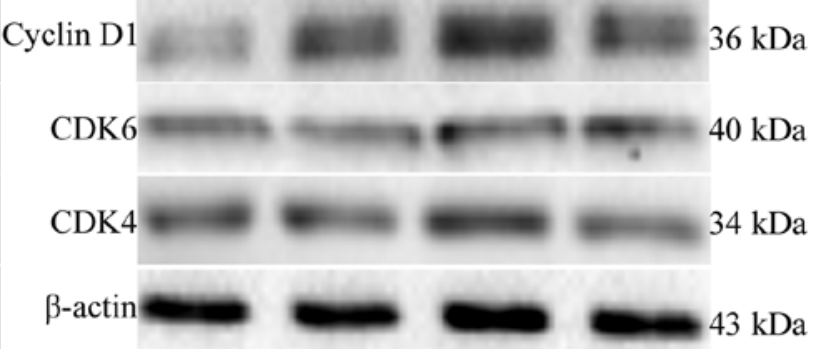

D

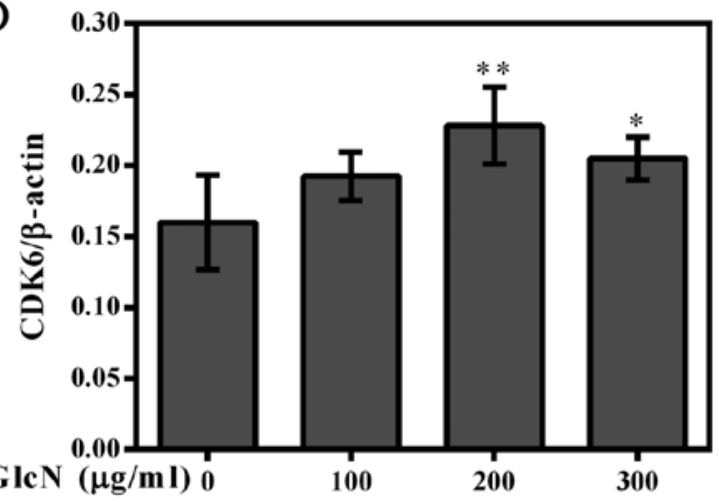

$\mathrm{F}$

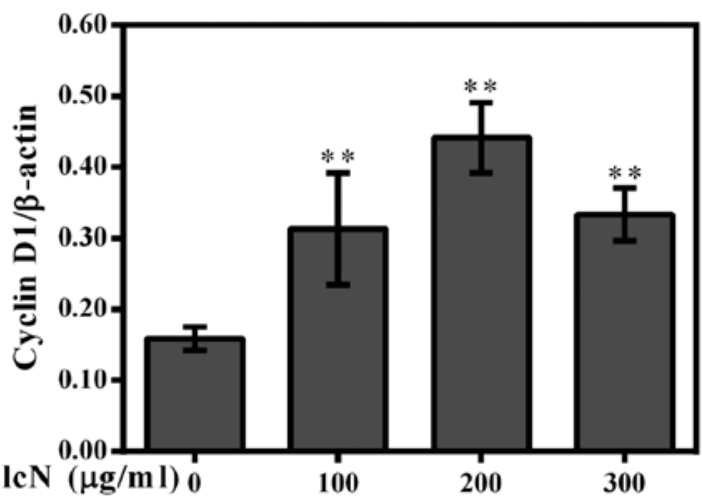

$\mathrm{H}$

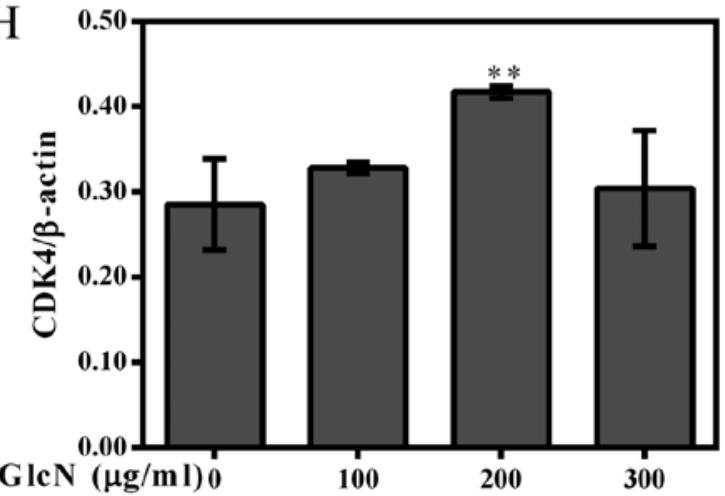

Figure 3. GlcN increases the expression levels of CDK4, CDK6 and cyclin D1. (A) mRNA expression levels of CDK4, CDK6 and cyclin D1 were analyzed by reverse transcription-polymerase chain reaction. (C-E) Semi-quantification of CDK4, CDK6 and cyclin D1 mRNA expression. (B) Western blot analysis of the protein expression levels of CDK4, CDK6 and cyclin D1. $\beta$-actin was used as an internal control. (F-H) Semi-quantification of the CDK4, CDK6 and cyclin D1 protein expression. ${ }^{*} \mathrm{P}<0.05,{ }^{* *} \mathrm{P}<0.01$ compared with the untreated cells. $\mathrm{CDK}$, cyclin-dependent kinase; GlcN, glucosamine.

GlcN promotes the expression and nuclear translocation of $\beta$-catenin. $\beta$-catenin is a well-known inducer of chondrocyte proliferation and a cytoplasmic protein, which interacts with TCF/LEF proteins to activate target genes, including cyclin D1 (23). The present study detected $\beta$-catenin nuclear translocation and expression using immunofluorescence, and western blotting and RT-PCR, respectively (Figs. 4 and 5). The present results demonstrated that GlcN may promote the mRNA and protein expression levels of $\beta$-catenin (Fig. 5A, $\mathrm{B}, \mathrm{F}$ and $\mathrm{J}$ ). The effects of GlcN on the nuclear translocation 


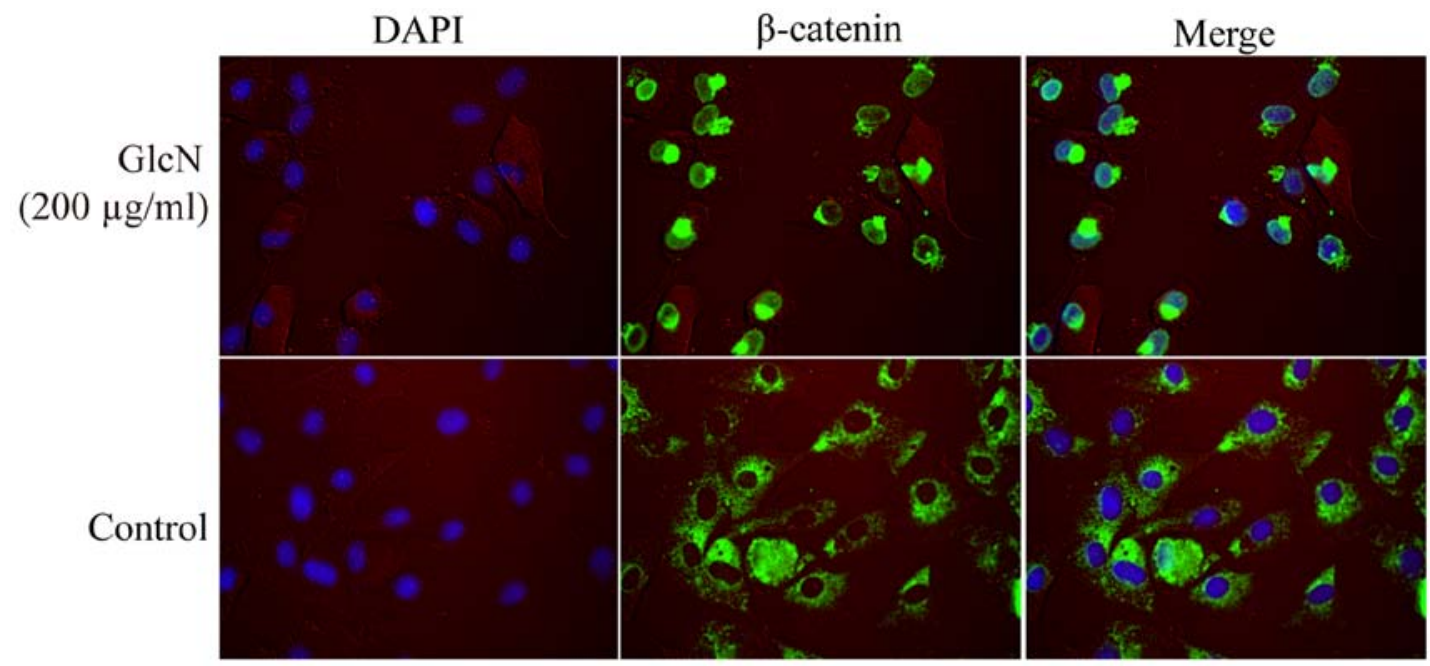

Figure 4. GlcN promotes $\beta$-catenin nuclear translocation. Chondrocytes were treated with $200 \mu \mathrm{g} / \mathrm{ml} \mathrm{GlcN}$ for $72 \mathrm{~h}$, followed by immunofluorescence staining for $\beta$-catenin (green). The nuclei were stained with DAPI (blue). $\beta$-catenin immunostaning was predominantly localized in the nucleus following treatment with GlcN. GlcN, glucosamine.

of $\beta$-catenin were further confirmed by immunofluorescence staining.

Immunofluorescence staining revealed that $\mathrm{GlcN}$ markedly enhanced translocation of $\beta$-catenin into the nucleus (Fig. 4). Following treatment with GlcN, $\beta$-catenin staining was more intense and was localized in the nucleus, whereas $\beta$-catenin was predominantly localized in the cytoplasm in the untreated cell group. These results indicated that GlcN may promote the expression and nuclear localization of $\beta$-catenin.

GlcN increases Wnt-4 and Frizzled-2 expression, and decreases $G S K-3 \beta$ expression. $\beta$-catenin is a downstream intracellular signaling molecule of the $\mathrm{Wnt} / \beta$-catenin signaling pathway (24). The Wnt/ $\beta$-catenin signaling pathway inhibits phosphorylation of $\beta$-catenin, thus resulting in its stabilization, cytoplasmic accumulation and subsequent nuclear translocation. A previous study demonstrated that the $\mathrm{Wnt} / \beta$-catenin signaling pathway has an important function in controlling a wide range of developmental processes, including cell proliferation (24). Therefore, to detect whether the effects of $\mathrm{GlcN}$ on chondrocyte proliferation are associated with the Wnt/ $\beta$-catenin signaling pathway, the mRNA and protein expression levels of relevant factors in the $\mathrm{Wnt} / \beta$-catenin signaling pathway were detected. The results indicated that the mRNA and protein expression levels of Wnt-4 and Frizzled-2 were increased in the GlcN-treated chondrocytes compared with in untreated cells (Fig. 4A-C, E, G and I), whereas the mRNA and protein expression levels of GSK-3 $\beta$ were reduced compared with in untreated cells (Fig. 4D and H). These results indicated that the effects of GlcN on chondrocyte proliferation may be associated with the $\mathrm{Wnt} / \beta$-catenin signaling pathway.

Cyclin D1 and $\beta$-catenin expression is partly decreased following inhibition of the Wnt/ $\beta$-catenin signaling pathway. With regards to the aforementioned results of the present study, it is unclear whether the $\mathrm{Wnt} / \beta$-catenin signaling pathway serves a crucial role in the regulation of chondrocyte proliferation. Therefore, DKK- 1 was used to block the Wnt/ $\beta$-catenin signaling pathway. The results revealed that the expression levels of cyclin D1 and $\beta$-catenin were partly inhibited by DKK-1 (Fig. 6). These results further strengthened the evidence that GlcN may participate in the regulation of chondrocyte proliferation via the $\mathrm{Wnt} / \beta$-catenin signaling pathway.

\section{Discussion}

Functional alterations to chondrocytes have an important role in cartilage damage, and the proliferation of chondrocytes is required for the maintenance of cellular volume (25). Numerous studies have indicated that an association exists between cartilage degradation and chondrocyte apoptosis $(26,27)$. Therefore, promotion of chondrocyte proliferation is essential and may be a potential therapeutic strategy for the treatment of OA. In the present study, the results demonstrated that GlcN promoted chondrocyte proliferation via the $\mathrm{Wnt} / \beta$-catenin signaling pathway. Firstly, the results indicated that GlcN treatment promoted chondrocyte proliferation via the promotion of cell cycle progression. The results of an MTT assay revealed that GlcN promoted chondrocyte viability in a dose- and time-dependent manner. Furthermore, the results of a flow cytometric analysis demonstrated that the percentage of chondrocytes in $\mathrm{G}_{0} / \mathrm{G}_{1}$ phase was markedly decreased, whereas the percentage of chondrocytes in $\mathrm{S}$ phase was significantly increased in cells treated with GlcN compared with in untreated cells. The cell cycle is responsible for cell proliferation; however, there are two restriction points, $G_{1} / S$ and $G_{2} / S$, within the cell cycle. The $G_{1} / S$ restriction point begins during the initial synthesis of DNA and the $G_{2} / S$ restriction point starts at the beginning of mitosis. The $\mathrm{G}_{1} / \mathrm{S}$ restriction point is more important since it determines which cell cycle phases the cells pass through (6). The present results indicated that GlcN treatment promoted chondrocyte proliferation via the promotion of cell cycle progression.

To further determine the mechanism underlying the effects of GlcN on chondrocyte proliferation, the protein expression levels of cyclins and CDKs were detected. Cell cycle progression is predominantly regulated via CDKs and cyclins, which 

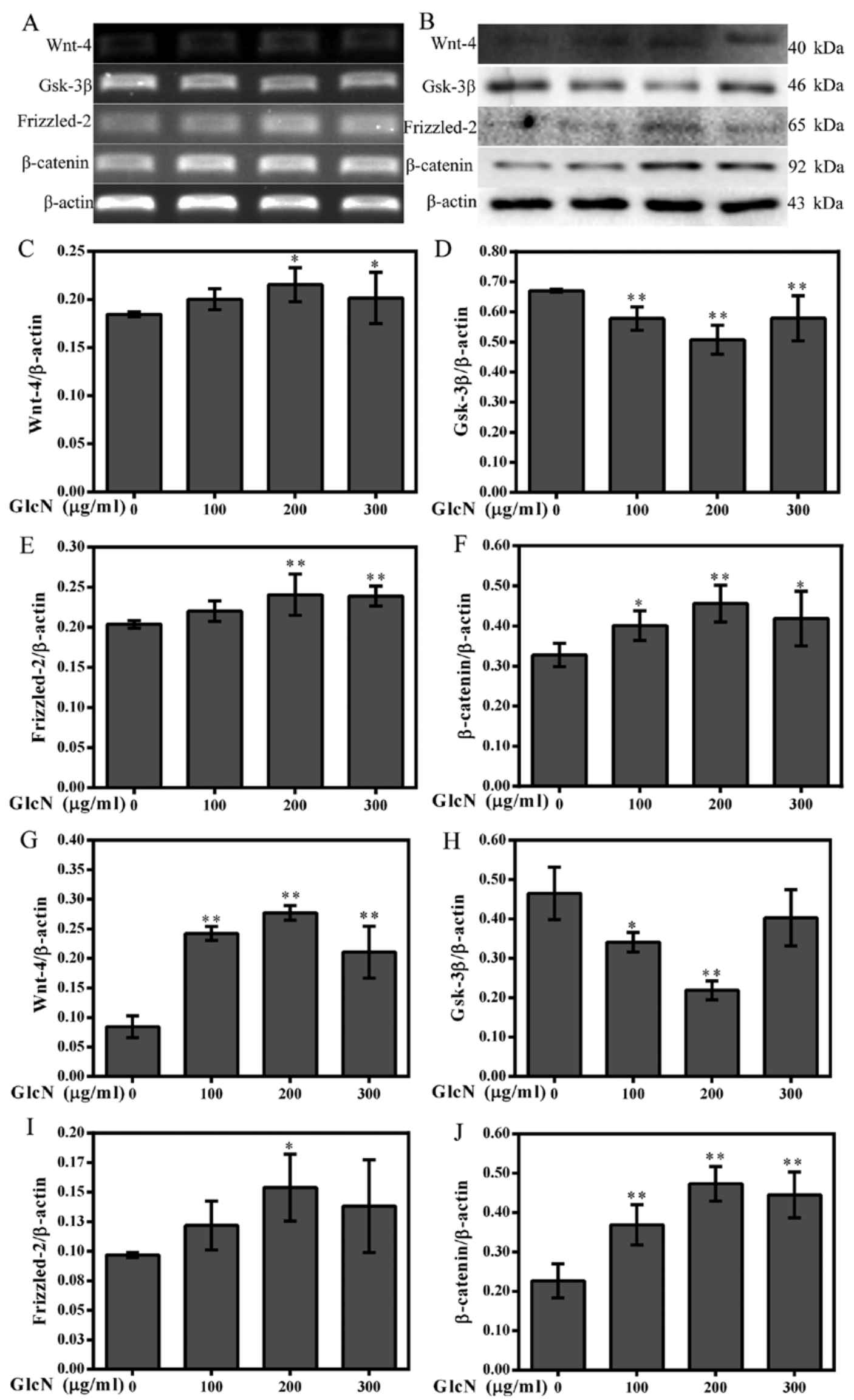

Figure 5. GlcN increases the expression of Wnt-4, Frizzled-2 and $\beta$-catenin, and decreases the expression of GSK-3 $\beta$. (A) mRNA expression levels of Wnt-4, Frizzled-2, $\beta$-catenin and GSK-3 $\beta$ were determined by reverse transcription-polymerase chain reaction. (B) Western blot analysis was used to detect the protein expression levels of Wnt-4, Frizzled-2, $\beta$-catenin and GSK-3 $\beta$. $\beta$-actin was used as an internal control. (C-F) Semi-quantification of Wnt-4, Frizzled-2, $\beta$-catenin and GSK-3 $\beta$ mRNA expression. (G-J) Semi-quantification of Wnt-4, Frizzled-2, $\beta$-catenin and GSK-3 $\beta$ protein expression. ${ }^{*} \mathrm{P}<0.05$, ${ }^{* *} \mathrm{P}<0.01$ compared with untreated cells. GlcN, glucosamine; GSK-3 $\beta$, glycogen synthase kinase-3 $\beta$. 
A
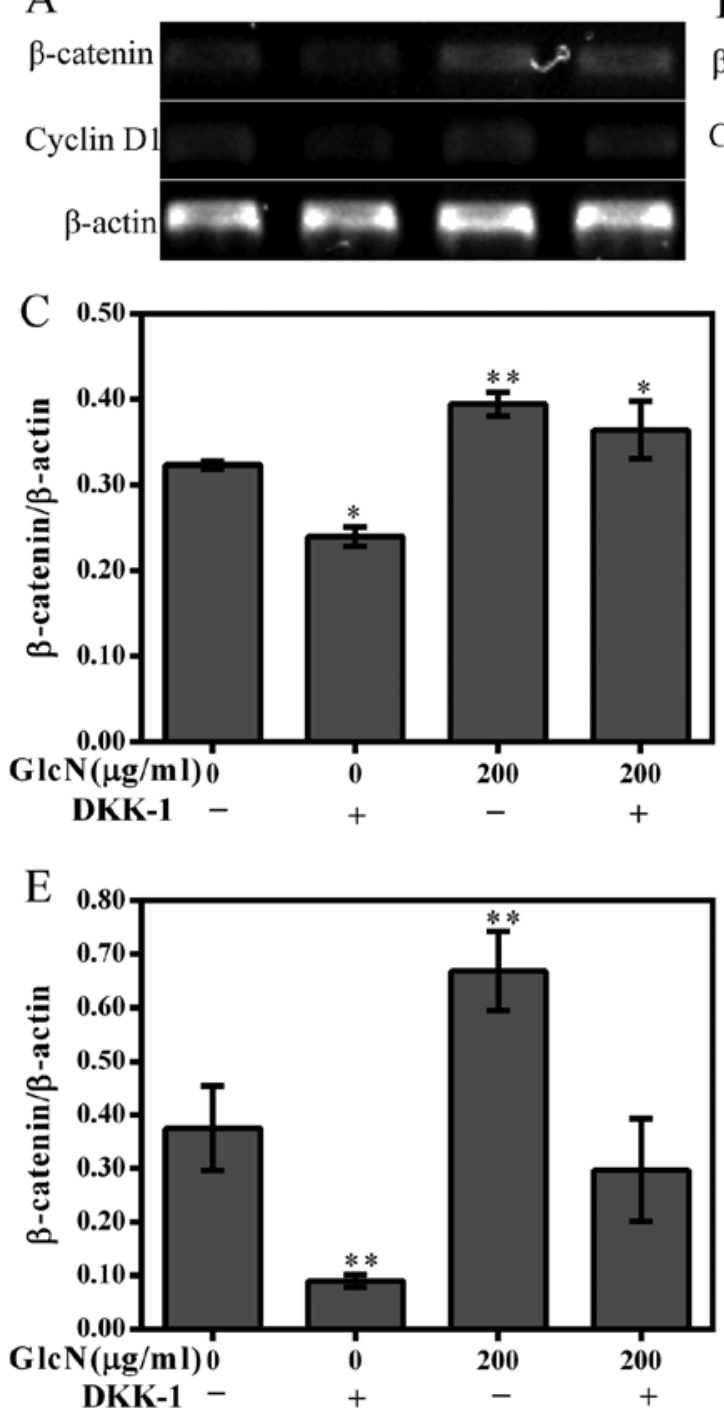

B
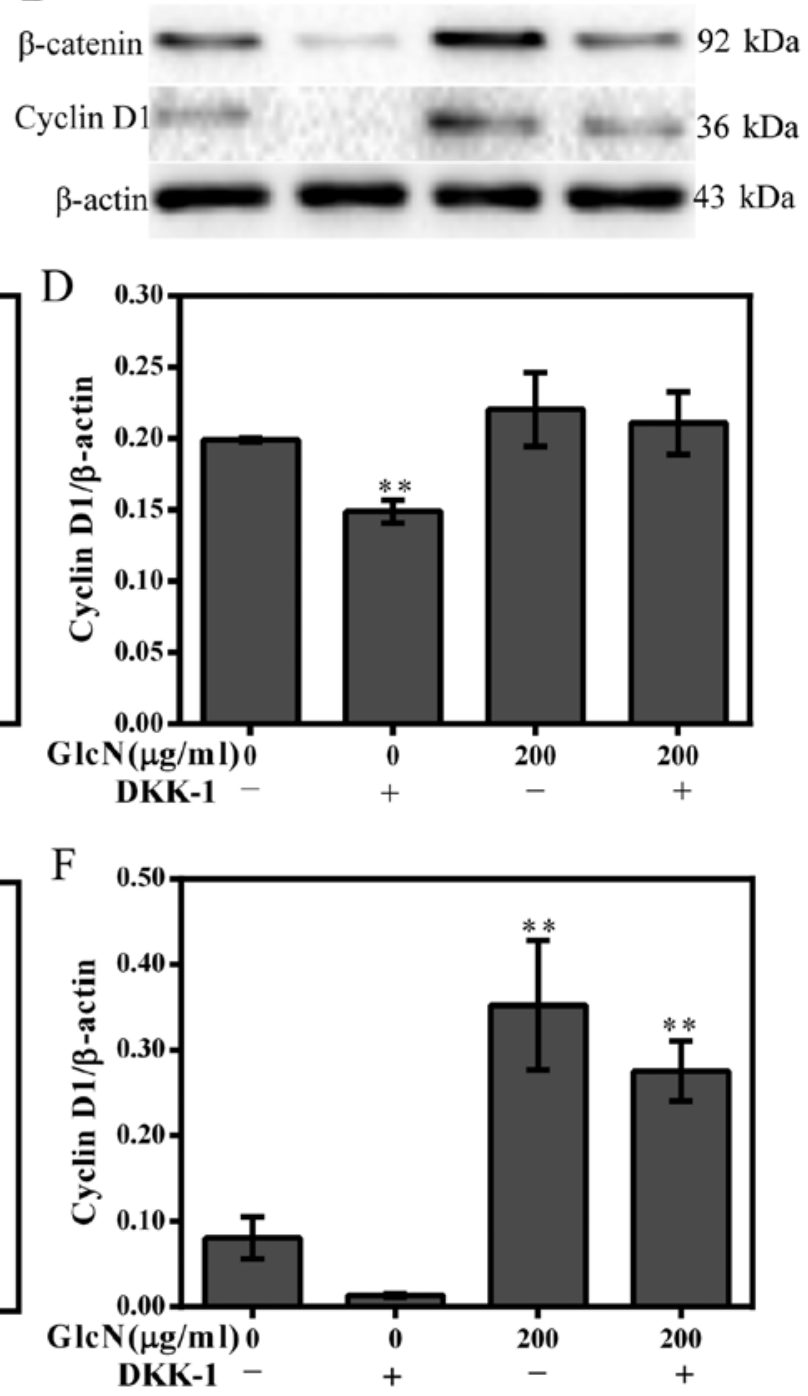

Figure 6. Inhibitory effects of DKK-1 on GlcN-induced cyclin D1 and $\beta$-catenin expression. Chondrocytes were treated with $0.2 \mu \mathrm{g} / \mathrm{ml}$ DKK-1, and were incubated with GlcN $(200 \mu \mathrm{g} / \mathrm{ml})$ in the presence or absence of DKK-1. (A) $\beta$-catenin and cyclin D1 mRNA expression was detected using reverse transcription-polymerase chain reaction. (B) $\beta$-catenin and cyclin D1 protein expression was detected using western blotting. (C and D) mRNA expression levels of $\beta$-catenin and cyclin D1 were semi-quantified. (E and F) Protein expression levels of $\beta$-catenin and cyclin $\mathrm{D} 1$ were semi-quantified. ${ }^{*} \mathrm{P}<0.05,{ }^{* *} \mathrm{P}<0.01$ compared with untreated cells. DKK-1, Dickkopf-1; GlcN, glucosamine.

are two basic protein families of the cell cycle control system. Various cyclin/CDKs exert their functions in different phases of the cell cycle. In the cell cycle, cyclin D1 is the active regulatory factor for the procession of $\mathrm{G}_{1} / \mathrm{S}$ phase, and is important to cell proliferation (28). Cyclin D1 forms a complex with CDKs, which proceed through the $\mathrm{G}_{1} / \mathrm{S}$ phase transition by translocating to the nucleus and inducing cell signaling (29). It has been reported that cyclin D/CDK4-6 and cyclin E/CDK2 allow progression in $G_{1}$ and elicit the $G_{1} / S$ transition (30). The present results suggested that GlcN treatment may promote the progression of chondrocytes from $\mathrm{G}_{1}$ to $\mathrm{S}$ phase by regulating cyclin D1, CDK4 and CDK6 expression. It has also been reported that GlcN increases cell migration, cell cycle regulatory protein expression (cyclin D1, CDK4, cyclin E and CDK2), and the percentage of $\mathrm{S}$ phase cells in mouse embryonic stem cells (31). In addition, GlcN and chondroitin sulfate association increases tibial epiphyseal growth plate proliferation and bone formation in ovariectomized rats (22).
It has previously been indicated that the expression of cyclin D1 is directly regulated by numerous transcription factors, including $\beta$-catenin $(21,32)$. Through interaction with TCF/LEF and coactivators, $\beta$-catenin is able to activate the downstream target genes of cyclin D1, thus resulting in cell proliferation (33). As the key effector of the Wnt/ $\beta$-catenin signaling pathway, $\beta$-catenin is responsible for transducing the signal to the nucleus and initiating transcription of Wnt-specific genes, which are responsible for the control of cell fate decisions in several cells and tissues (34). Our previous study also indicated that the $\mathrm{Wnt} / \beta$-catenin signaling pathway mediates rat chondrocyte proliferation (21). In the present study, the results suggested that GlcN may increase the expression levels of Wnt-4, Frizzled-2 and $\beta$-catenin, whereas it may decrease GSK-3 $\beta$ expression. In addition, GlcN significantly promoted the translocation of $\beta$-catenin into the nucleus, thus suggesting that GlcN promotes chondrocyte proliferation via the Wnt/ $\beta$-catenin signaling pathway. 
To confirm whether GlcN enhances chondrocyte proliferation via the $\mathrm{Wnt} / \beta$-catenin signaling pathway, DKK-1 was used to inhibit the Wnt $/ \beta$-catenin signaling pathway. DKK-1 binds to LRP5/6 on target cells, thus resulting in the inhibition of Wnt/ $\beta$-catenin signaling $(35,36)$. In the $\mathrm{Wnt} / \beta$-catenin signaling pathway, GSK-3 $\beta$ is thought to be phosphorylated in the absence of Wnt signaling, consequently inducing the degradation of $\beta$-catenin and decreasing cyclin D1 expression. The present results suggested that the expression levels of $\beta$-catenin and cyclin D1 were partly inhibited by DKK-1, further indicating that GlcN may promote chondrocyte proliferation through the Wnt/ $\beta$-catenin signaling pathway. These results indicated GlcN may participate in the regulation of chondrocyte proliferation via the $\mathrm{Wnt} / \beta$-catenin signaling pathway. In addition, it also demonstrated that chondrocyte proliferation was not completely dependent on the Wnt/ $\beta$-catenin signaling pathway.

In conclusion, the present results demonstrated that GlcN promotes the proliferation of chondrocytes via the Wnt/ $\beta$-catenin signaling pathway. However, it is undeniable that other signal pathways may also be involved in this regulation. Therefore, further studies are required to verify this conclusion using cell and animal models.

\section{Acknowledgements}

The authors appreciate the research platform of Fujian Key Laboratory of Rehabilitation Technology, Fuzhou, Fujian, China.

\section{Funding}

The present study was supported by the National Natural Science Foundation of China (grant no. 81573998), the Science and Technology Platform Construction Project of Fujian Science and Technology Department (grant no. 2015Y2001), the Natural Science Foundation of Fujian Province (grant no. 2016J01395) and the Fund of Fujian University of Traditional Chinese Medicine (grant no. X2016020-Key Project).

\section{Availability of data and materials}

The datasets used and/or analyzed during the current study are available from the corresponding author on reasonable request.

\section{Authors' contributions}

YM and WZ, performed the MTT assay, cell cycle analysis and immunohistochemistry, and were major contributors in writing the manuscript. HC and XS performed the RT-PCR analysis and western blot analysis. PL performed the cell culture and analyzed the data. XiaL, XihL and HY designed and carried out the experiments. All authors read and approved the final manuscript.

\section{Ethics approval and consent to participate}

The present study was approved by the Ethics Committee of Fujian University of Traditional Chinese Medicine (Fuzhou, China)

\section{Consent for publication}

Not applicable.

\section{Competing interests}

The authors declare that they have no competing interests.

\section{References}

1. Hada S, Kaneko H, Sadatsuki R, Liu L, Futami I, Kinoshita M, Yusup A, Saita Y, Takazawa Y, Ikeda H, et al: The degeneration and destruction of femoral articular cartilage shows a greater degree of deterioration than that of the tibial and patellar articular cartilage in early stage knee osteoarthritis: A cross-sectional study. Osteoarthritis Cartilage 22: 1583-1589, 2014.

2. Moo EK, Han SK, Federico S, Sibole SC, Jinha A, Abu Osman NA, Pingguan-Murphy B and Herzog W: Extracellular matrix integrity affects the mechanical behaviour of in-situ chondrocytes under compression. J Biomech 47: 1004-1013, 2014.

3. Gao Y, Liu S, Huang J, Guo W, Chen J, Zhang L, Zhao B, Peng J, Wang A, Wang Y, et al: The ECM-cell interaction of cartilage extracellular matrix on chondrocytes. BioMed Res Int 2014: 648459, 2014.

4. Onumah OE, Jules GE, Zhao Y, Zhou L, Yang H and Guo Z: Overexpression of catalase delays G0/G1- to S-phase transition during cell cycle progression in mouse aortic endothelial cells Free Radic Biol Med 46: 1658-1667, 2009.

5. Lamb R, Lehn S, Rogerson L, Clarke RB and Landberg G: Cell cycle regulators cyclin D1 and CDK4/6 have estrogen receptor-dependent divergent functions in breast cancer migration and stem cell-like activity. Cell Cycle 12: 2384-2394, 2013.

6. Li X, Chen J, Liang W, Li H, Liu F, Weng X, Lin P, Chen W, Zheng $\mathrm{C}, \mathrm{Xu} \mathrm{H}$, et al: Bushen Zhuangjin Decoction promotes chondrocyte proliferation by stimulating cell cycle progression. Exp Ther Med 9: 839-844, 2015.

7. Lin AC, Seeto BL, Bartoszko JM, Khoury MA, Whetstone H, Ho L, Hsu C, Ali SA and Alman BA: Modulating hedgehog signaling can attenuate the severity of osteoarthritis. Nat Med 15: $1421-1425,2009$.

8. Appleton CT, Usmani SE, Mort JS and Beier F: Rho/ROCK and MEK/ERK activation by transforming growth factor-alpha induces articular cartilage degradation. Lab Invest 90: 20-30, 2010.

9. Yuasa T, Otani T, Koike T, Iwamoto M and Enomoto-Iwamoto M: Wnt/beta-catenin signaling stimulates matrix catabolic genes and activity in articular chondrocytes: Its possible role in joint degeneration. Lab Invest 88: 264-274, 2008.

10. Yasuhara R, Ohta Y, Yuasa T, Kondo N, Hoang T, Addya S, Fortina P, Pacifici M, Iwamoto $M$ and Enomoto-Iwamoto $M$ : Roles of $\beta$-catenin signaling in phenotypic expression and proliferation of articular cartilage superficial zone cells. Lab Invest 91: 1739-1752, 2011.

11. Rosenbluh J, Wang $X$ and Hahn WC: Genomic insights into WNT/ $\beta$-catenin signaling. Trends Pharmacol Sci 35: 103-109, 2014.

12. Wang Y,Li YP, Paulson C, Shao JZ, Zhang X, Wu M and Chen W: Wnt and the Wnt signaling pathway in bone development and disease. Front Biosci (Landmark Ed) 19: 379-407, 2014.

13. Long F, Schipani E, Asahara H, Kronenberg H and Montminy M: The CREB family of activators is required for endochondral bone development. Development 128: 541-550, 2001.

14. Miclea RL, Karperien M, Bosch CA, van der Horst G, van der Valk MA, Kobayashi T, Kronenberg HM, Rawadi G, Akçakaya P, Löwik CW, et al: Adenomatous polyposis coli-mediated control of beta-catenin is essential for both chondrogenic and osteogenic differentiation of skeletal precursors. BMC Dev Biol 9: 26, 2009.

15. Nagaoka I, Igarashi $M$ and Sakamoto K: Biological activities of glucosamine and its related substances. Adv Food Nutr Res 65: 337-352, 2012.

16. Reginster JY, Neuprez A, Lecart MP, Sarlet N and Bruyere O: Role of glucosamine in the treatment for osteoarthritis. Rheumatol Int 32: 2959-2967, 2012. 
17. Salazar J, Bello L, Chávez M, Añez R, Rojas J and Bermúdez V: Glucosamine for osteoarthritis: Biological effects, clinical efficacy, and safety on glucose metabolism. Arthritis (Egypt) 2014: 432463, 2014.

18. Henrotin $\mathrm{Y}$ and Lambert $\mathrm{C}$ : Chondroitin and glucosamine in the management of osteoarthritis: An update. Curr Rheumatol Rep 15: 361, 2013.

19. Li H, Li X, Liu G, Chen J, Weng X, Liu F, Xu H, Liu X and Ye H: Bauhinia championi (Benth.) Benth. polysaccharides upregulate Wnt $/ \beta$-catenin signaling in chondrocytes. Int J Mol Med 32: 1329-1336, 2013

20. Lin P, Weng X, Liu F, Ma Y, Chen H, Shao X, Zheng W, Liu X Ye $\mathrm{H}$ and Li X: Bushen Zhuangjin decoction inhibits TM-induced chondrocyte apoptosis mediated by endoplasmic reticulum stress. Int J Mol Med 36: 1519-1528, 2015.

21. Weng X, Lin P, Liu F, Chen J, Li H, Huang L, Zhen C, Xu H, Liu X, Ye H, et al: Achyranthes bidentata polysaccharides activate the $\mathrm{Wnt} / \beta$-catenin signaling pathway to promote chondrocyte proliferation. Int J Mol Med 34: 1045-1050, 2014.

22. Yu F, Li X, Cai L, Li H, Chen J, Wong X, Xu H, Zheng C, Liu X and $\mathrm{Ye} \mathrm{H}$ : Achyranthes bidentata polysaccharides induce chondrocyte proliferation via the promotion of the G1/S cell cycle transition. Mol Med Rep 7: 935-940, 2013.

23. Shtutman M, Zhurinsky J, Simcha I, Albanese C, D'Amico M, Pestell R and Ben-Ze'ev A: The cyclin D1 gene is a target of the beta-catenin/LEF-1 pathway. Proc Natl Acad Sci USA 96: 5522-5527, 1999.

24. Huelsken J and Birchmeier W: New aspects of Wnt signaling pathways in higher vertebrates. Curr Opin Genet Dev 11: 547-553, 2001

25. Chan BY, Fuller ES, Russell AK, Smith SM, Smith MM, Jackson MT, Cake MA, Read RA, Bateman JF, Sambrook PN, et al: Increased chondrocyte sclerostin may protect against cartilage degradation in osteoarthritis. Osteoarthritis Cartilage 19: 874-885, 2011

26. Kim HT, Lo MY and Pillarisetty R: Chondrocyte apoptosis following intraarticular fracture in humans. Osteoarthritis Cartilage 10: 747-749, 2002.

27. D'Lima DD, Hashimoto S, Chen PC, Colwell CW Jr and Lotz MK: Human chondrocyte apoptosis in response to mechanical injury. Osteoarthritis Cartilage 9: 712-719, 2001.
28. Löwenheim H, Reichl J, Winter H, Hahn H, Simon C, Gültig K, Müller A, Zenner HP, Zimmermann U and Knipper M: In vitro expansion of human nasoseptal chondrocytes reveals distinct expression profiles of $\mathrm{G} 1$ cell cycle inhibitors for replicative, quiescent, and senescent culture stages. Tissue Eng 11: 64-75, 2005.

29. Sherr CJ: D-type cyclins. Trends Biochem Sci 20: 187-190, 1995.

30. Ghiani C and Gallo V: Inhibition of cyclin E-cyclin-dependent kinase 2 complex formation and activity is associated with cell cycle arrest and withdrawal in oligodendrocyte progenitor cells. J Neurosci 21: 1274-1282, 2001.

31. Jeon JH, Suh HN, Kim MO and Han HJ: Glucosamine-induced reduction of integrin $\beta 4$ and plectin complex stimulates migration and proliferation in mouse embryonic stem cells. Stem Cells Dev 22: 2975-2989, 2013.

32. Yano F, Kugimiya F, Ohba S, Ikeda T, Chikuda H, Ogasawara T, Ogata N, Takato T, Nakamura K, Kawaguchi $\mathrm{H}$, et al: The canonical Wnt signaling pathway promotes chondrocyte differentiation in a Sox9-dependent manner. Biochem Biophys Res Commun 333: 1300-1308, 2005.

33. Kikuchi A: Regulation of beta-catenin signaling in the Wnt pathway. Biochem Biophys Res Commun 268: 243-248, 2000.

34. Valenta T, Hausmann $G$ and Basler K: The many faces and functions of $\beta$-catenin. EMBO J 31: 2714-2736, 2012.

35. Ye S, Wang J, Yang S, Xu W, Xie M, Han K, Zhang B and Wu Z: Specific inhibitory protein Dkk-1 blocking Wnt/ $\beta$-catenin signaling pathway improve protectives effect on the extracellular matrix. J Huazhong Univ Sci Technolog Med Sci 31: 657-662, 2011

36. Gifre L, Ruiz-Gaspà S, Monegal A, Nomdedeu B, Filella X, Guañabens N and Peris P: Effect of glucocorticoid treatment on Wnt signalling antagonists (sclerostin and Dkk-1) and their relationship with bone turnover. Bone 57: 272-276, 2013.

This work is licensed under a Creative Commons Attribution-NonCommercial-NoDerivatives 4.0 International (CC BY-NC-ND 4.0) License. 